\title{
Precision arboriculture: a new approach to tree risk management based on geomatics tools
}

S. De Petris, R. Berretti, F. Sarvia, E. Borgogno-Mondino

S. De Petris, R. Berretti, F. Sarvia, E. Borgogno-Mondino, "Precision arboriculture: a new approach to tree risk management based on geomatics tools," Proc. SPIE 11149, Remote Sensing for Agriculture, Ecosystems, and Hydrology XXI, 111491G (21 October 2019); doi: 10.1117/12.2532778 


\title{
Precision arboriculture: a new approach to tree risk management based on geomatics tools
}

\author{
S. De Petris* ${ }^{1 \mathrm{la}}$, R. Berretti ${ }^{\mathrm{a}}$, F. Sarvia ${ }^{\mathrm{a}}$, E. Borgogno-Mondino ${ }^{\mathrm{a}}$ \\ ${ }^{a}$ DISAFA - Department of agriculture, forest and food sciences of Torino University, L.go P. \\ Braccini 2, Grugliasco, TO, Italy
}

\begin{abstract}
In green extensive context, RPAS (Remotely Piloted Aerial Systems) can provide information with a high geometric resolution. The photogrammetric survey shows the possibility of measuring morphometric parameters of forest stand or individual trees. The free accessibility to Copernicus Sentinel-2 (S2) data addresses to hypothesize scenarios where satellite spectral information and high geometric resolution of RPAS photogrammetric survey, jointly used, determine a deeper knowledge of tree characteristics. Study area is located within the "La Mandria" park (NW Italy). Survey was operated by a DJI-Phantom4 RPAS (GSD images $=5 \mathrm{~cm}$ ). Image photogrammetric processing was achieved by AGISOFT Photoscan v1.2.4. The resulting point cloud was filtered and a raster DSM (Digital Surface Model) was generated with a GSD $=10 \mathrm{~cm}$. The correspondent CHM (Canopy Height Model) was computed by difference using a DTM (Digital Terrain Model) available from the regional cartographic archive. An object-based approach (watershed segmentation) aimed at bordering tree crowns as vector polygons was run. Some tree stability parameters were obtained from CHM by zonal statistics for each crown that was also spectrally characterized (to explore its vigor) using a S2 image time series. The proposed method finds applications in the arboricultural field (ornamental context) for the survey of tree inventory data; the detected parameters can be used as input data for tree risk assessment/management models, especially in extensive contexts representing a new approach to single tree risk management based on innovative technologies and algorithms that can reduce costs of ground control/survey campaigns.
\end{abstract}

Keywords: Precision arboriculture, RPAS photogrammetry, Sentinel-2, multispectral data, tree risk

\section{INTRODUCTION}

Urban trees provide visual, aesthetic, social and economic benefits to humans ${ }^{1,2}$ absorbing pollution, enhancing ecological diversity and having a beneficial impact on psychological wellbeing ${ }^{3}$.

It's worth to remind that trees could die due to drought, disease, insect attack and catastrophic events (e.i. high winds) or their stems and branches could break up while they are still green. In situations where trees and people must live in close proximity it is necessary define where a tree has become an unacceptable risk ${ }^{4}$. Risk of being killed or injured by a tree is extremely low ${ }^{2}$. In UK about 3 people per year are killed by tree in public places ${ }^{5,6}$ while in the United States about 31 people per year (note that U.S population is five times that of UK) ${ }^{7}$. In recent years, the tree potential to cause harm is increasing by climate change effects especially for how to concerns windstorm and tree diseases which are the main factors in tree failure phenomena ${ }^{8-10}$. From this point of view, a greater attention has to be paid to evaluate risks and benefits of trees. Public or private owners must, consequently, monitor the risk associated to their trees in respect of public safety. Ordinarily, trees management in urban context is carried out by arboriculture techniques ${ }^{11-13}$; but whereas trees are located in extensive contexts, like natural parks, is necessary to take into account some management issues: i) spatial extension where trees are located; ii) heterogeneity of vegetative conditions of trees; iii) trees number; iv)

*samuele.depetris@unito.it; phone 0116705516; fax 0116705516.

Remote Sensing for Agriculture, Ecosystems, and Hydrology XXI, edited by Christopher M. U. Neale,

Antonino Maltese, Proc. of SPIE Vol. 11149,111491G · C 2019 SPIE

CCC code: $0277-786 \mathrm{X} / 19 / \$ 21 \cdot$ doi: $10.1117 / 12.2532778$ 
relationship between a safe exploitation of trees and their protection/conservation; v) costs of ground controls and technical interventions. The latter especially represents the major problem related to the followings:

1. ground controls/technical interventions in extensive contexts have higher costs if compared to urban ones, mainly due to the larger size of monitored areas that require longer movements, possibly, in environmentally asper situations.

2. to optimize generally limited financial resources, it is necessary to define, as much objectively as possible, priority zones to be assessed.

Geomatics can effectively support these requirements by integrating survey, spatial modelling and simulation of several scenarios able to give an overview of possible evolution of risk ${ }^{14}$. In this work, it is authors' intention to present a new approach for tree management in extensive context hereinafter called "Precision Arboriculture" (PA) based on innovative technologies like RPAS-based (Remotely Piloted Aircraft System) photogrammetry, and satellite (namely Copernicus Sentinel-2 data) multispectral image processing, with aim of measuring tree parameters useful to give a spatial modelling of tree failure risk to be managed within an operative decision support system (DSS). According to the current Italian technical standards ${ }^{15}$ and international best practices adopted in the arboriculture field ${ }^{16}$ authors developed a tree risk index (TRI) based on the QTRA (Quantified Tree Risk Assessment) approach ${ }^{2,17,18}$. QTRA relates tree stability, as described by analytic assessment, with potential damageable targets. Tree stability was modelled with reference to the Static Integrated Assessment (SIA) methodology ${ }^{19,20}$, that was modified introducing a self-developed Vegetation index derived from satellite multispectral imagery.

RPAS photogrammetry was adopted to define the geometrical proprieties of trees in the study area. Copernicus Sentinel2 multispectral data were used to investigate tree vigour along time (with reference to the 2015-2018 years). Potential targets related to tree failure were mapped according to the roads layer of the available technical map from the Cartographic Office of the Piemonte Region (NW Italy). All information was integrated along a modified QTRA risk model and a risk map was generated for the study area. Finally, a preliminary economical evaluation was achieved to demonstrate potential money saving that such an approach can determine in respect of a more traditional one.

\section{MATERIALS AND METHODS}

\subsection{Study Area}

The study area is located in the La Mandria Piemonte Regional Park (NW-Italy) sited near Torino municipality and, consequently, characterized by a high level of fruition from citizens. Broadleaf species with dominance of pedunculate oak (Quercus robur L.) is the main vegetation type in the area. This work focused on the surroundings of the main park entry (about $13 \mathrm{ha}$ ) where a monumental avenue ( $7.7 \mathrm{ha}$ ) with 60 ancient trees (200 years old) is coupled with a more ordinary forested area (5.3 ha). Park boundaries are limited by walls, making users' access to the park controlled. Access is limited from 8 a.m. to 8 p.m. (12 hours per day) all along the year. The area was chosen for both the presence of young and old trees, the latter requiring a peculiar management to guarantee the necessary balance between protection and safe utilization of the park. 


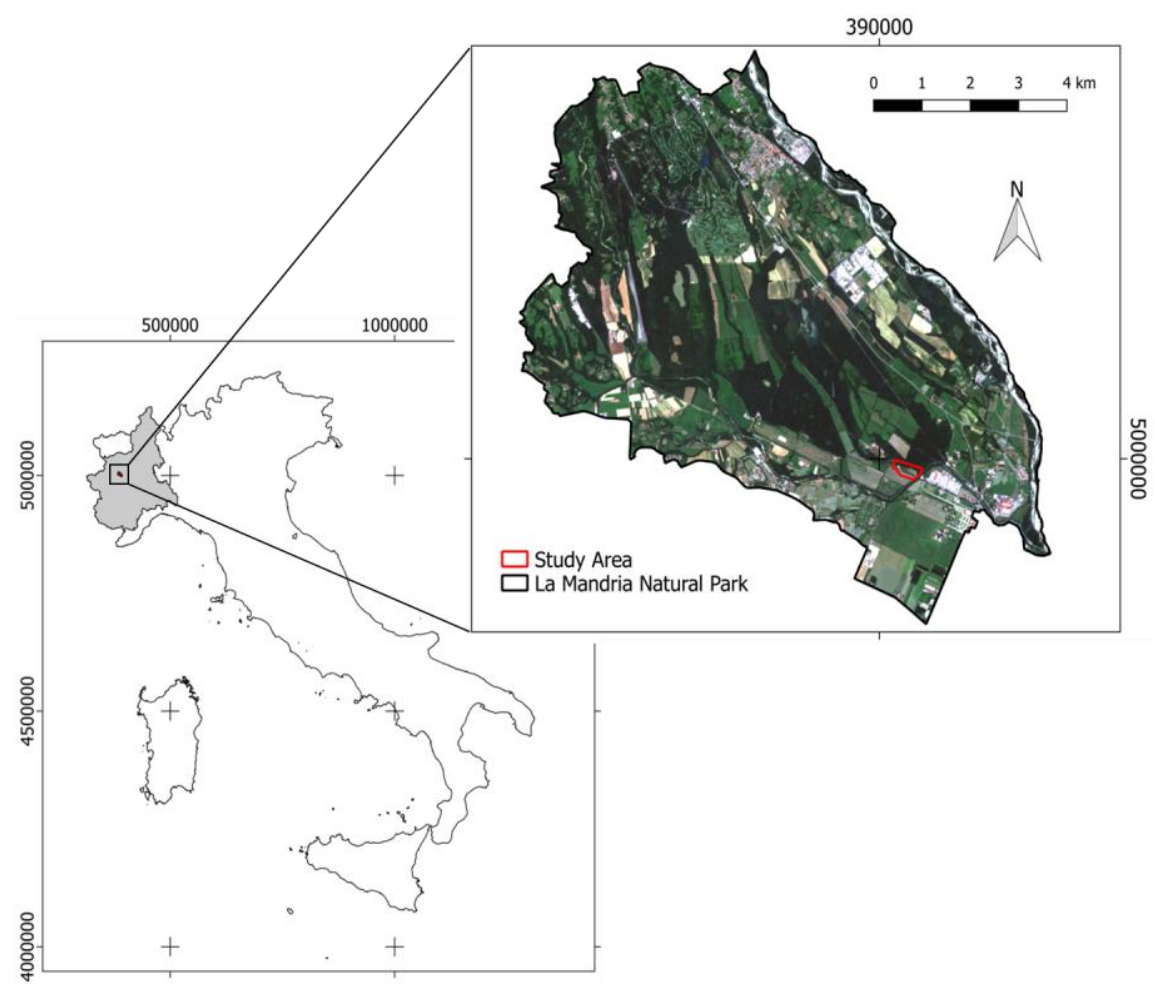

Fig. 1 - The study area localization (Reference Frame: WGS84 UTM 32N)

\subsection{Available Dataset}

\subsubsection{RPAS-derived data}

A photogrammetric survey was operated by a DJI Phantom4 UAV (Unnamed Aerial Vehicles) equipped with a 12.4 Megapixel RGB camera having the following features: focal length $=8.60 \mathrm{~mm}$, physical pixel sixe $=$ $2.344 \mu \mathrm{m}$ and CMOS sensor size $=13.2 \times 8.8 \mathrm{~mm}$. Flight was performed with a mean speed of $3.1 \mathrm{~ms}^{-1}$ determining a baseline of $9.6 \mathrm{~m}$, average flying height was $90 \mathrm{~m}$ with a forward and side overlap of $93 \%$ and $85 \%$, respectively. Nine markers, sizing $0.5 \times 0.5 \mathrm{~m}$, were positioned within and around the avenue and their position surveyed by N-RTK (Network RTK) technique using a Leica 1200 GNSS receiver. Point position 3D accuracy (MAE - Mean Absolute Error) was about $0.03 \mathrm{~m}$. Selected reference frame was WGS84 UTM 32N. These points were successively used as Ground control points (GCPs) during the image block orientation ${ }^{21,22}$. Flight time and GNSS survey required about 100 minutes to detect 13 ha. RPAS data processing was performed by Agisoft PhotoScan v 1.2.4.

\subsubsection{Sentinel-2 Dataset}

A total of 267 Sentinel-2 (A/B) Level 2A multispectral images (hereinafter called S2) were obtained from the CNES-Theia provider, covering a sensing period between $27^{\text {th }}$ May 2015 and $7^{\text {th }}$ October 2018. Level 2A dataset is supplied already orthoprojected and at-the-ground reflectance calibrated; mask layers mapping clouds, shadows, water and snow are released with images, as well. S2 images technical characteristics are reported in table 1. From this dataset the correspondent NDVI maps were computed and a Vegetation Index Maps Time Series (VITS) generated. VITS was used to compute a synthetic index somehow representing the tree vegetative vigour condition in the observed period (detailed index description is given in section 2.3.5). 
Table 1 - S2 image characteristics retrieved by Theia Provider.

\begin{tabular}{|cccc|}
\hline & $\begin{array}{c}\text { Central wavelength } \\
(\mathbf{n m})\end{array}$ & $\begin{array}{c}\text { Bandwidth } \\
(\mathbf{n m})\end{array}$ & $\begin{array}{c}\text { Nominal } \\
\text { Geometric resolution by Theia CNES provider }\end{array}$ \\
\hline B2 & 490 & 98 & $10 \mathrm{~m}$ \\
B3 & 560 & 45 & $10 \mathrm{~m}$ \\
B4 & 665 & 38 & $10 \mathrm{~m}$ \\
B5 & 705 & 19 & $10 \mathrm{~m}(20 \mathrm{~m}$ native resolution $)$ \\
B6 & 740 & 18 & $10 \mathrm{~m}(20 \mathrm{~m}$ native resolution $)$ \\
B7 & 775 & 28 & $10 \mathrm{~m}(20 \mathrm{~m}$ native resolution $)$ \\
B8 & 840 & 145 & $10 \mathrm{~m}$ \\
B8A & 865 & 33 & $10 \mathrm{~m}(20 \mathrm{~m}$ native resolution $)$ \\
B11 & 1610 & 143 & $10 \mathrm{~m}(20 \mathrm{~m}$ native resolution $)$ \\
B12 & 2200 & 242 & $10 \mathrm{~m}(20 \mathrm{~m}$ native resolution $)$ \\
\hline
\end{tabular}

\subsubsection{Ground Data}

A field campaign was also performed to get a reference dataset of tree features in the area. For each tree the following parameters were surveyed/computed using the Field-map ${ }^{\odot}$ instrument ${ }^{23}$ : tree position, diameter at the breast height $(\mathrm{DBH})$, species, tree height $(\mathrm{H})$, flat crown projection $(\mathrm{P})$; globally, 134 trees were surveyed (Fig. 2). As far as hardware technology is concerned the Field-map () system is composed of a TruPulse 200/B laser range-finder coupled with an inclinometer and a reflecting signal mounted on a movable pole. Measurements were carried out with a distance between target (pole) and operator never exceeding $40 \mathrm{~m}$. This instrument is said to have a nominal accuracy of $\pm 0.25^{\circ}$ and $\pm 0.2 \mathrm{~m}$ for angular and distance measures, respectively.

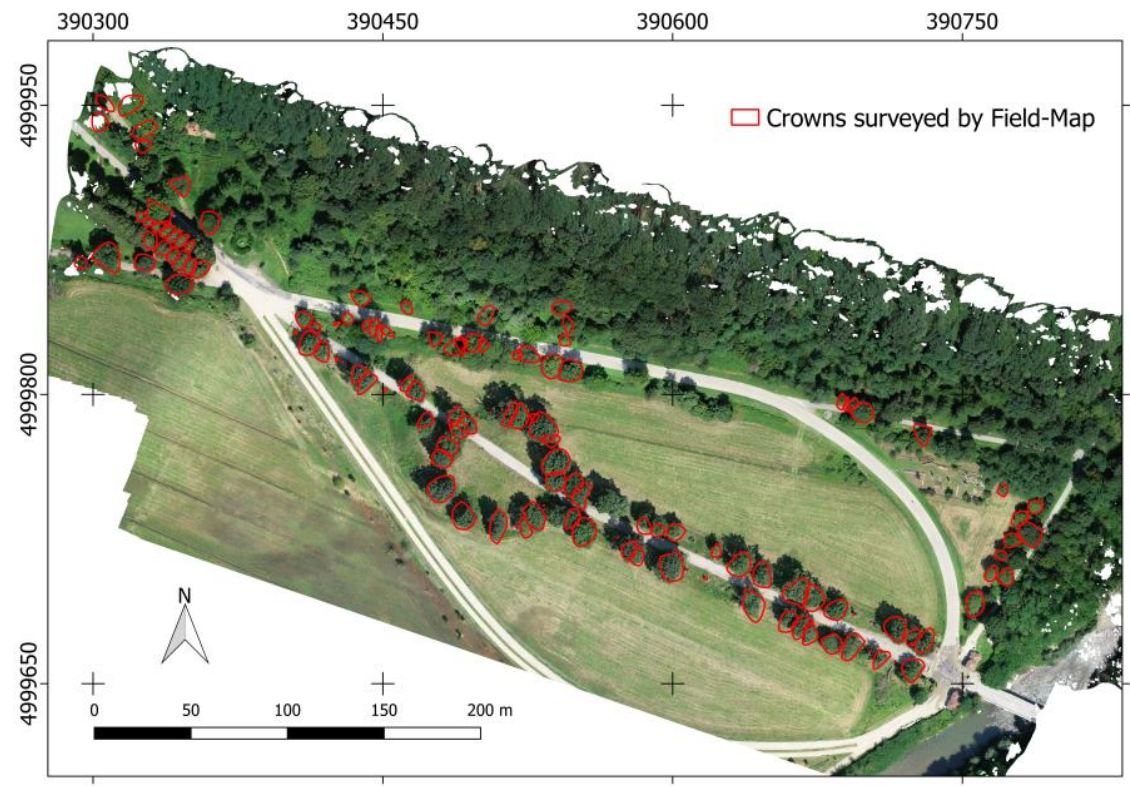

Figure 2 - Crown vector map generated by Field-Map during ground survey. 


\subsubsection{Auxiliary data}

A line vector layer mapping local road network was obtained from the Piemonte Region Geoportal (BDTRE geodatabase, nominal scale $=1: 10000$ ), assuming that tree failure risk depend on the proximity between roads and trees. Reference system of the layer was WGS84 UTM 32N. Its content was updated at 2018.

\subsection{Data Processing}

Integration of digital photogrammetry and optical remote sensing can greatly empower a DSS aimed at managing tree risk, especially in those extensive (large) contexts where a priority for ground controls is required. DSS is, in fact, expected to figure out the most critical situations making possible an optimization of ground surveys. In this operational scenario, image information from RPAS, S2 multispectral data and existing maps can be considered as the main DSS inputs; differently, a map of a tree risk index (TRI) is the expected output. Data processing was achieved according to the workflow showed in figure 3 . Acronyms meaning is given in the following paragraphs. 


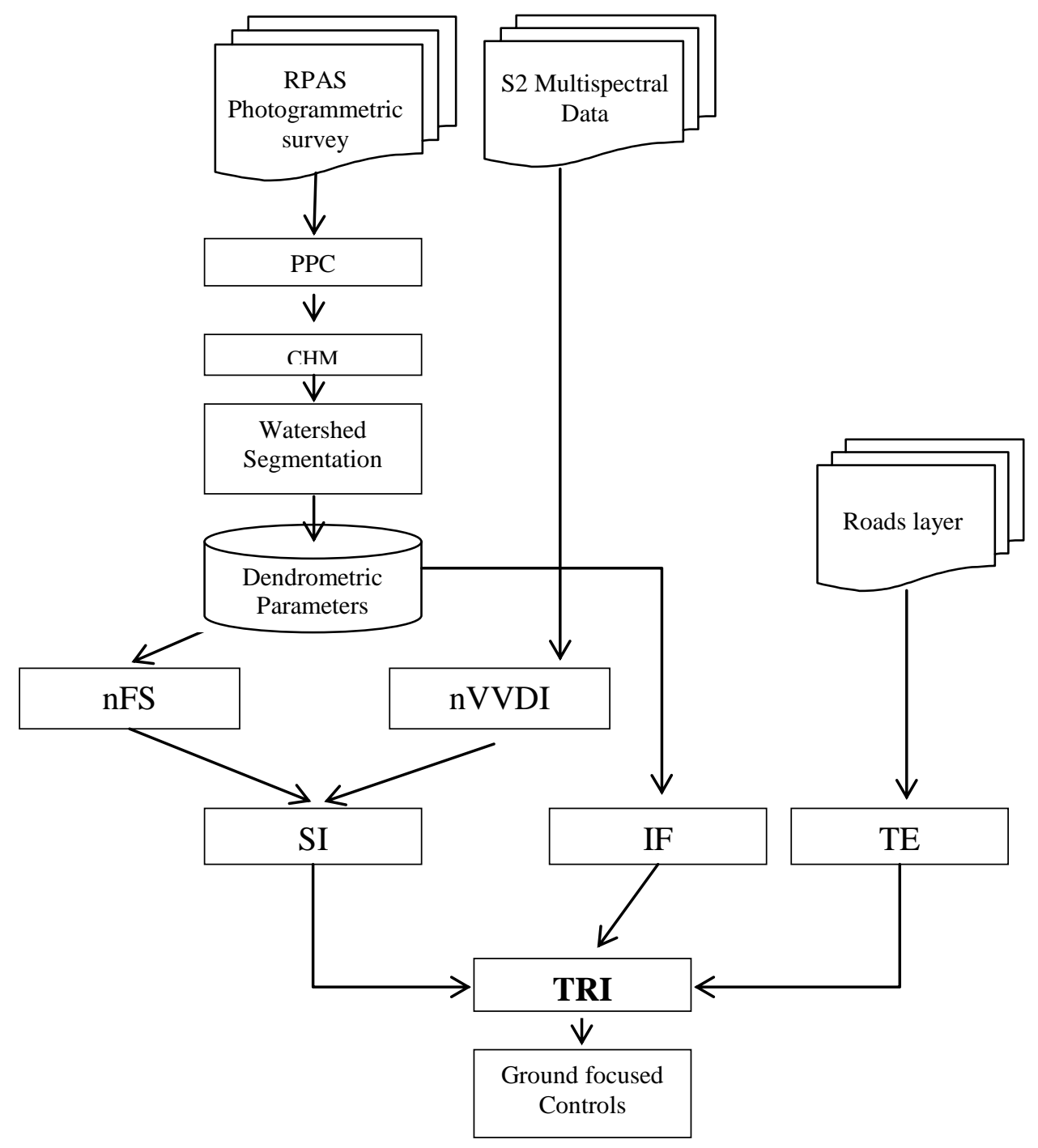

Figure 3 - Proposed workflow used to create Tree risk DSS.

\subsubsection{Image Block Bundle Adjustment}

According to the above mentioned flight plan, 773 frames were finally acquired during the survey having an average GSD of about $5 \mathrm{~cm}$; they were used to generate a photogrammetric point cloud (PPC), a DSM (Digital Surface Model) and an orthomosaic of the area. Image block bundle adjustment was operated with reference to the previously described 9 markers, preventively positioned at the ground level.

\subsubsection{CHM generation}

PPC was generated by Agisoft Photoscan and exported in .LAS format, that is typical of the ALS (Aerial laser scanner) point clouds. This made possible to operate PPC filtering, point classification (ground - Not ground) and regularization in a more controllable way using the LAStools libraries ${ }^{24}$. The DSM was finally generated with a grid size of $0.1 \mathrm{~m}$. The correspondent CHM (Canopy Height Model) was computed by grid differencing between DSM and the DTM (Digital Terrain Model) freely available from Piedmont Region geoportal. The 
latter was natively supplied with a GSD of $5 \mathrm{~m}$; consequently it was oversampled (Nearest Neighbour) to $0.1 \mathrm{~m}$ to fit the DSM resolution. All values lower than $2 \mathrm{~m}$ were finally masked out from the obtained CHM, being certainly not representative of tree crowns.

\subsubsection{From CHM to dendrometric parameters}

Some forest parameters were obtained from CHM with reference to the single tree. The possibility of measuring tree features strictly depends on the capability of mapping single tree crown. Consequently, an image segmentation step, based on the watershed algorithm, was achieved using SAGA Gis v.7 software. A tree crown vector layer (C) was finally generated (Fig. 4). With reference to the segments the maximum tree Height (Hmax) was computed by zonal statistics working on CHM. It is worth to remind that Hmax is a direct measure, making its value more reliable if compared with more traditional methods where Hmax is derived as an indirect measure with unknown accuracy ${ }^{25,26}$. From this point of view, the proposed methodology based on digital photogrammetry, makes possible to give a reliable estimate of both Hmax and all derived measures uncertainty (e.g. DBH and biomass).

DBH estimate was computed with reference to Hmax, by adopting the most used model in forestry to retrieved DBH: the so called "Inverse Ispometer Curve" (IIC, eq. 1) ${ }^{27}$. IIC starting from tree height can estimate the correspondent tree DBH. IIC was calibrated according to the available ground measures. After calibration, the model relating DBH to Hmax resulted the one of eq. 1.

$$
\mathrm{DBH}=0.0073 \mathrm{H}^{1.5576}
$$

DBH is a measure of the total stem diameter and it include the bark that doesn't significantly contribute to tree stability ${ }^{28}$. Consequently and more properly authors preferred to refer to the relative Diameter Under Bark (DUB) using equation 2 by Laar and his collaborators ${ }^{29}$.

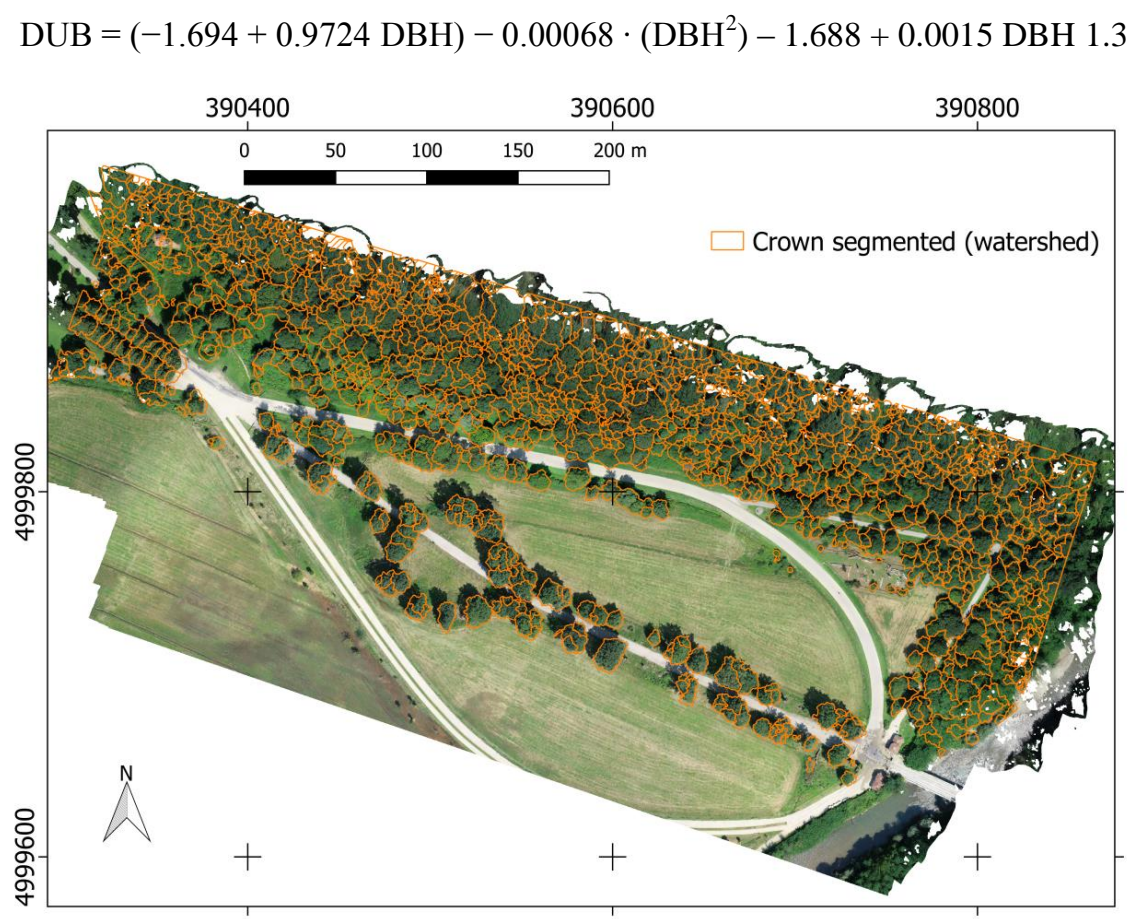

Figure 4 - Layer $\mathrm{C}$ representing the polygon-crown delineated by watershed algorithm. 


\subsubsection{Biomechanical model}

Tree stability assessment was achieved by the adoption of SIA biomechanical model ${ }^{20}$, which requires DBH and Hmax as inputs giving a Safety Factor (SF) as output. SF represents the ratio between the DUB of theoretical stem that could resist to a project wind of $32 \mathrm{~ms}^{-1}$ and the real DUB having a range of variation between 0 and $+\infty$. The model considers tree size and mechanical proprieties of a given wood species. In this work we used average values for broadleaf species (oak, ash, lime, alder) proposed by L. Wessolly ${ }^{20}$. Unstable tree shows ordinarily SF value under $150^{20,30}$. For each tree the correspondent SF value was therefore computed (Fig. 5), according to DBH and Hmax values. SF=150 was assumed as the threshold under which tree have potential low stability conditions and over which they should not suffer from any stability problem. The focus was consequently on the SF range $0-150$. All computed SF values under 150 were normalized between $0-1$ (hereinafter called $\mathrm{x}$ ); all values exceeding 150 were coded as 1 . A new index (hereinafter called $\mathrm{nFS}$ ) was computed as the difference between 1 (instability) and $\mathrm{x}$ (SF normalized value). $\mathrm{nFS}$ is intended to represent the distance from a critic biomechanical state: values closed to 1 mean low stability conditions; values closed to 0 mean high stability.

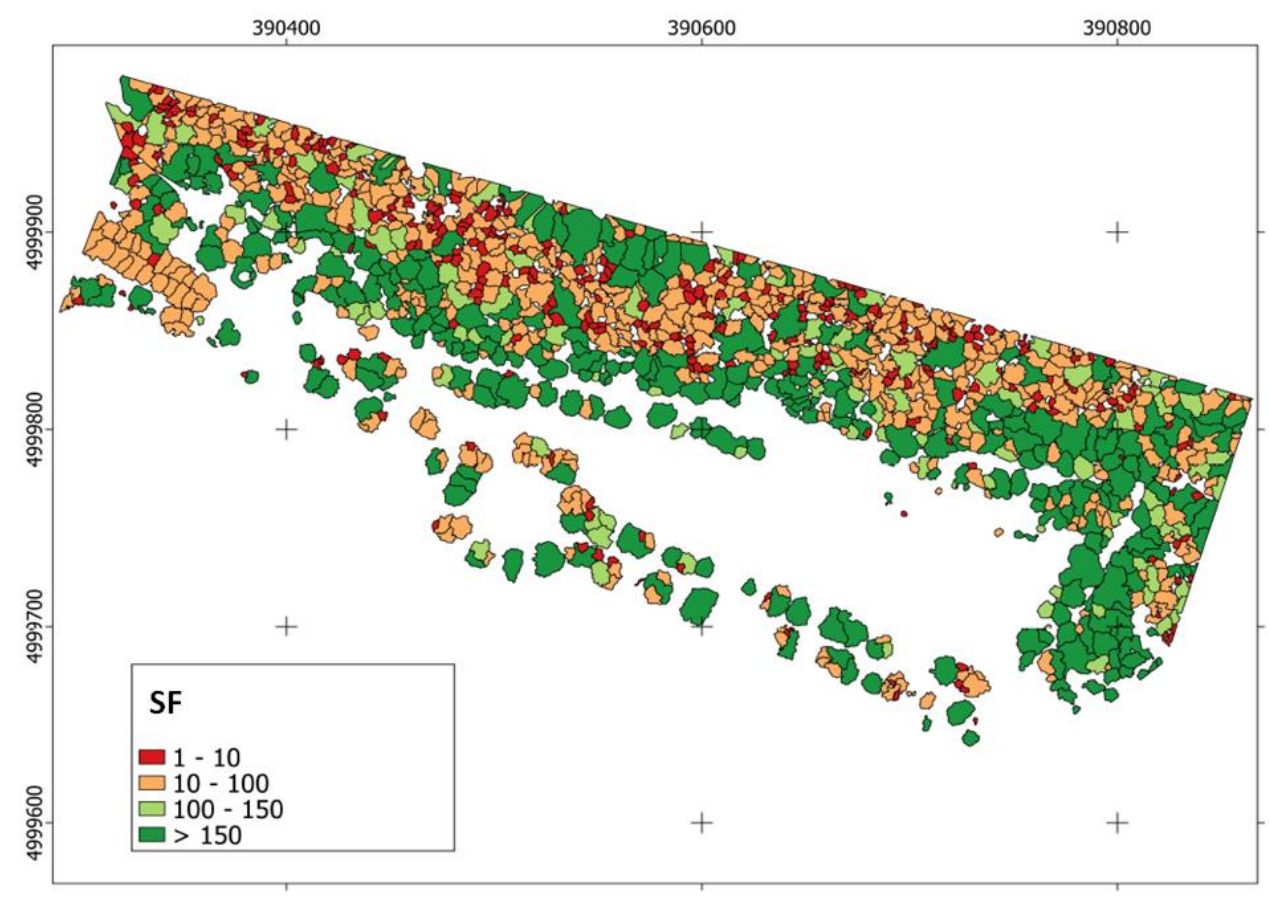

Figure 5 - Single tree SF distribution.

\subsubsection{Vegetation Vigor Index}

Starting from the 267 downloaded S2 images, the correspondent NDVI maps were generated and stacked along a NDVI Time series (NTS). Since many scenes were affected by cloud cover, a self-developed routine was implemented in $I D L v s$. 8.0 to mask out bad observations and regularize them with a time step of 5 days, resulting in a new NTS made of 73 images per year. A further filtering, based on FFT (Fast Fourier Transform $)^{31}$, was finally applied to minimize NDVI fluctuations, caused by remaining outliers, and emphasize periodic fluctuations of the phenological trend. For each year of the filtered NTS (4 years were considered) the maximum NDVI value was calculated (NDVImax) and plotted against time. NDVImax allows to more robustly compare NDVI between different years summarizing the maximum phenological expression that is strictly 
correlated with health state of vegetation ${ }^{32,33}$. Theoretically, this index expresses vigor of crown in a given vegetative period. Assuming NDVImax as a proxy of plant annual health status, the analysis trend over time of this index provides useful information for interpretation of latent or chronic phenomena of vigor's decline. A NDVImax trend line was modelled by regression (first order polynomial) for the 2015-2018 period at pixel level; its gain value was assumed as increase/decrease vigor index (hereafter called VVI- Vegetation Vigor Index). VVI was assumed as proxy of the average vigor change rate during the 4 years of observation. To investigate the variability of this index, the theoretical range within which it can move was analytically calculated. Taking into account that a vegetated surface ordinarily shows NDVI values ranging between 0.3 and $1^{34-37}$, a $0.7 \mathrm{NDVI}$ range of variation was considered; the theoretical gain of the steepest line relating time (4 years) and NDVImax is given by the ratio $0.7 / \mathrm{n} \_$years. For the case study $\mathrm{n} \_$years was 4 and consequently the maximum theoretical gain was 0.175 . Accordingly, VVI can therefore be said to vary between -0.175 to + 0.175 . The index was therefore normalized between 0 and 1 to compute nVVI. Values of nVVI lower than 0.5 can be interpreted as loss of vegetation vigour; values higher than 0.5 can be interpreted as increasing of vigour; values around 0.5 can be interpreted as no variation in vigor strength during the considered period (Fig. 6). Since we were looking for a vegetation vigor decline and not just an increasing, all value under 0.5 were assumed as quantification of tree decline. Therefore, all $\mathrm{nVVI}$ lower than 0.5 were further normalized between 0 and 1, determining nVVDI (normalized Vegetation Vigor Decline Index). The resulting nVVDI map was oversampled by bilinear method from $10 \mathrm{~m}$ up to $0.5 \mathrm{~m}$ GSD. Bilinear method allowed to emulate a gradient of index within a crown, while oversampling permitted to mediate nVVDI value in the crown. For each segmented tree of the P layer the mean nVVDI value was computed. nVVDI was used as weight of SF value to obtain the stability index. Many authors reported that tree stability related to wood mechanical features is influenced by tree's state of health, especially when stability is compromised by wood rots. The ability to compartmentalize the pathogen mainly depends on the vigor of the plant ${ }^{13}$. Starting from these considerations a unhealthy tree is a plant more susceptible to parasitic attacks and with fewer resources to resist to pathological phenomena, therefore more inclined to failure ${ }^{38-41}$. It is worth to remind that a stress or pathological phenomena do not determine a direct propensity to failure; a unhealthy plant is not necessarily unstable, but has characteristics that make suspect a rapid development in pathogenic wood-induced decay and, therefore, greater general propensity to fall. In fact, considering two trees having the same SF is reasonably to pay major attention to the tree that shows a vigor decline, that maybe related to some pathologies, and so representing an higher hazard.

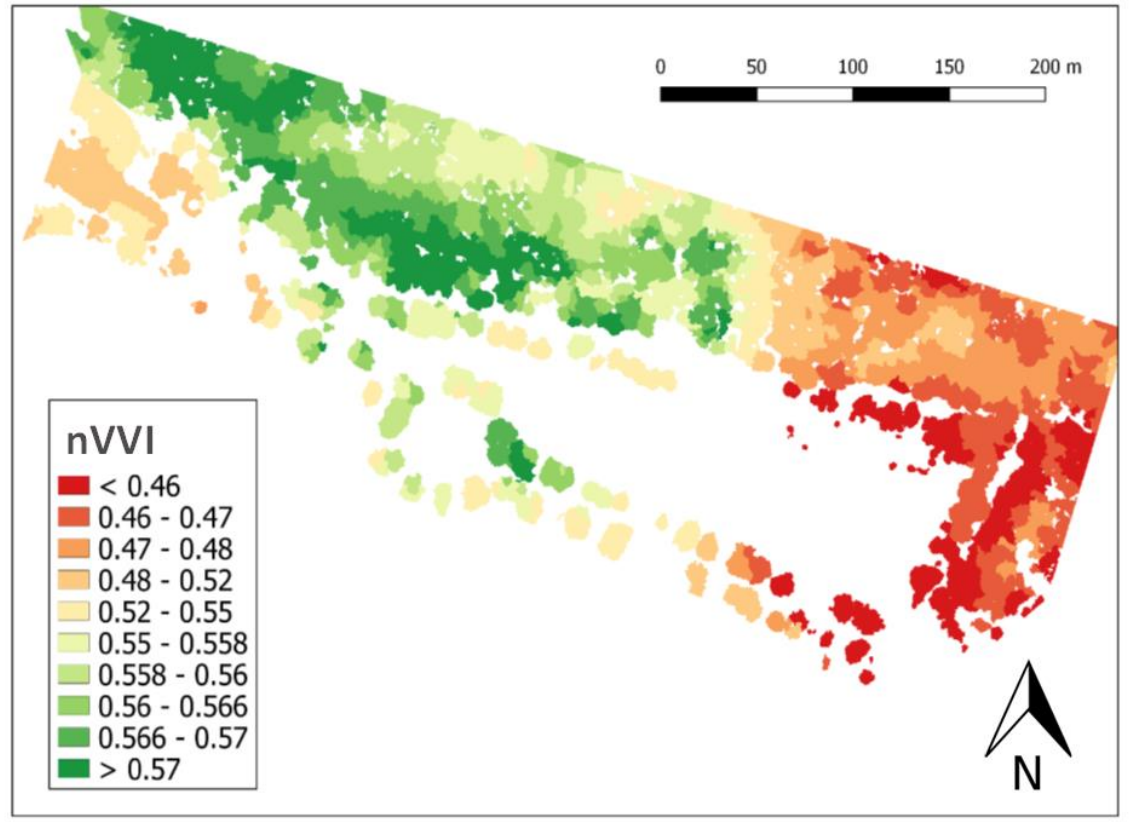

Figure 6 - nVVI distribution in the study area. 


\subsubsection{Quantified Tree risk Assessment (QTRA)}

A tree risk index (TRI) was obtained using QTRA method proposed by Ellison ${ }^{18}$ that uses the tree hazard components reported from the best practices defined by the International Society of Arboriculture ${ }^{16,42}$.Tree risk is composed by: (1) probability of failure (stability index), (2) potential impact and (3) target exposure. The system enables quantification of the independent probabilities of the three components, calculating their product (risk of harm, year-based) to be compared with a generally accepted level of risk. A probability of death or serious injury of $1 / 10000$ is suggested as the limit of acceptable risk to the public at large ${ }^{43}$. Using the $1 / 10000$ limit, all risks with a probability exceeding 1/10000 require mitigation actions to reduce the risk to an acceptable level ${ }^{17}$.

\section{Stability Index}

An accurate estimate of the probability that a tree or branch will fail is highly dependent on the skill and experience of the tree assessor. The adoption of SF as tree stability proxy is an objective tool to achieve the problem related to an empirical assessment and permits to define probability failure in quantitative way supporting management policies. The quantity (nFS x nVVDI) is a good proxy of tree stability (hereafter called Stability index - SI) considering both wood mechanical features, tree size, and tree vigor conditions. SI value closed to 1 means a high probability of tree failure related to both the presence of critic SF and nVVDI. In fact, trees with high SF value, stable from wood mechanical point of view, could show low nVVDI value meaning low vigor level, possibly due to ongoing pathologies or physiopathologies, determining a higher probability of failure ${ }^{13}$.

\section{Potential Impact}

The mass of a falling tree or branch contributes to the force that will occur during the impact with a target. A small, dead branch of less than $1 \mathrm{~cm}$ diameter is unlikely to cause significant harm while, on average, a falling branch with a diameter greater than $15 \mathrm{~cm}$ is likely to cause harm. According to QTRA an impact from a tree with a stem diameter of $60 \mathrm{~cm}$ has a 1/1 probability of causing maximum possible damage to most frequently encountered targets. Based on this empirical assumption QTRA method defines a model (Fig. 7) to quantify impact factor (IF) from DBH expressed as probability to cause harm after a hit with a target (people or cars). IF values next to 0 mean low probability of harm while value next to 1 mean high probability to cause harm, if a tree failed and subsists target under the potential tree fall area.

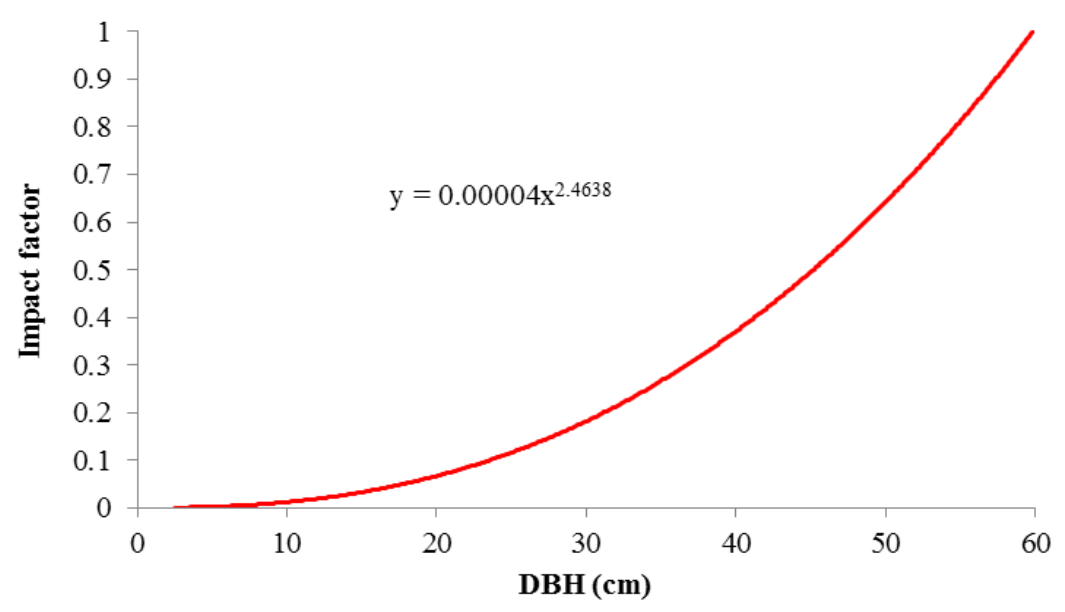

Figure 7 - IF- DBH relationship proposed by Ellison ${ }^{18}$. 


\section{Target exposure}

A unstable old tree in a inaccessible area in a natural forest unlikely could hit people; in fact although tree stability is low, the probability of finding someone in the tree fall area (TFA) is very low making a risk null. Therefore, the risk is strictly correlate to the use rate of the tree nearest area.

Considering that the direction of the fall is not known, to define the potential TFA we generated a circular buffer (1.5 times the Hmax value) around the centroid of segments of layer $\mathrm{C}$. This was done according to the international best arboricultural practices ${ }^{16}$. In the study area the park is open 12 hours per day all over the year generating a 0.5 of probability that someone walks within the park. Being difficult to model where people stay authors assumed that the highest probability of finding someone was in and around the main park roads. The available vector roads layer was intersected with the TFA; where no intersection was present the target exposure (TE) was codify as 0 since trees are far from the roads; in all other situation TE was coded as 0.5 .

\section{Tree risk index}

For each tree in the study area TRI was calculated as the product of SI x IP x TE. TRI can vary between 0 and 1 where values next to 1 mean high risk and values next to 0 mean low risk. Tree that show TRI values greater than $1 / 10000$ were considered critical.

\section{RESULTS AND DISCUSSIONS}

\subsection{Photogrammetric Measurements Accuracy}

Bundle Adjustment was operated with 9 GCPs having an accuracy of $0.035 \mathrm{~m}$ (WGS84 UTM 32N). After adjustment accuracies of photogrammetric resection computed by OLO (One-Leave-Out) method have the following values: $\sigma_{\mathrm{x}, \mathrm{y}}=$ $0.267 \mathrm{~m} ; \sigma_{\mathrm{z}}=0.229 \mathrm{~m} ; \sigma_{\mathrm{x}, \mathrm{y}, \mathrm{z}}=0.352 \mathrm{~m}$. The obtained dense PPC showed the characteristics reported in table 2.

Table 2- Characteristics of generated PPC

\begin{tabular}{|cc|}
\hline Variable & Value \\
$\mathrm{N}^{\circ}$ points & 36058127 \\
Point density $\left(\mathrm{Pm}^{-2}\right)$ & 249 \\
Mean points distance $(\mathrm{m})$ & 0.06 \\
\hline
\end{tabular}

\subsection{Dendrometric parameters accuracy}

A comparison between $\mathrm{P}$ and $\mathrm{C}$ was achieved by testing differences in terms of tree counting, Hmax and DBH. To compare $\mathrm{P}$ and $\mathrm{C}$ individuals an intersection was performed between $\mathrm{C}$ centroids and $\mathrm{P}$ polygons. Estimates errors are expressed as $\mathrm{MAE}^{44}$ (table 3 ) between ground based $(\mathrm{P})$ and photogrammetrically derived (C) measures. 
Table 3 - Dendrometric parameters accuracy (MAE) retrieved by CHM analysis in respect of ground data.

\begin{tabular}{|ccc|}
\hline Variable & Units & $\boldsymbol{M A E}$ \\
\hline $\mathrm{N}^{\circ}$ Tree & - & 11 \\
$\mathrm{DBH}$ & $\mathrm{m}$ & 0.05 \\
$\mathrm{H}$ & $\mathrm{m}$ & 0.32 \\
\hline
\end{tabular}

\subsection{Tree Risk Index}

Health and Safety Executive of UK government defined the Tolerability of Risk Framework (ToR) ${ }^{5}$ the following values for tolerable and unacceptable risk:

a) broadly Acceptable risk : less than 1/1000000, where no need to operate mitigation;

b) tolerable risk: between $1 / 100000$ and $1 / 10000$ where risk reduction should be considered in function of cost to mitigate risk respect benefits retrieved by tree ${ }^{2}$;

c) unacceptable risk: greater than $1 / 10000$, where is need to mitigated risk with arboricultural practices;

Assuming the previously mentioned ToR regions, TRI values in the study area have the distribution reported in figure 8 , showing that most of trees (75\%) have high risk level mainly due to the joint presence of ancient tree and streets in the study area.

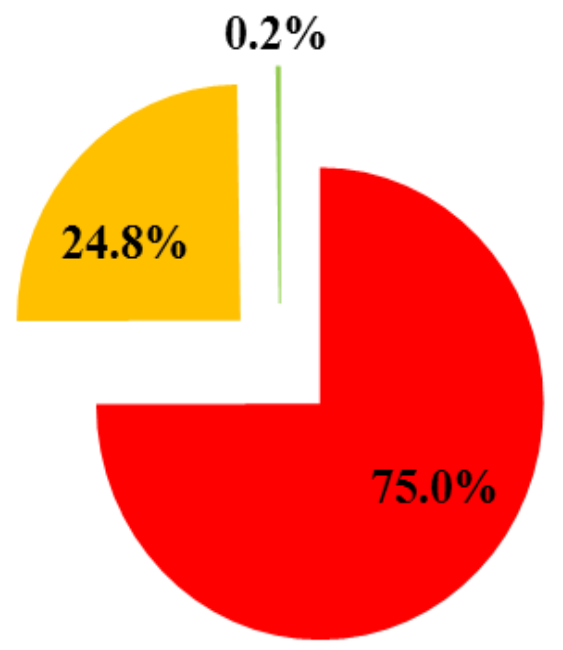

\section{Unacceptable Risk $\square$ Tolerable Risk $\square$ Acceptable Risk}

Figure 8 - Pie Chart of TRI classification (ToR) for the study area. 


\section{CONCLUSIONS}

The proposed methodology is intended to feed a DSS for tree managers with the aim of detecting and characterizing tree risk using a quantitative approach (PA). Those trees having critical TRI values have to be more accurately assessed by ground survey possibly supported by visual-instrumental analysis to define mitigation risk operation like: pruning, static bracing, target limitations or tree cut. The adoption of a quantitative index allows to balance costs and benefits in objective terms and support urban forestry or natural park policies. To encourage the technological transfer authors defined two scenarios that La Mandria park managers could adopt (Tab. 4). In the ordinary scenario $\left(n^{\circ} 1\right)$ the $100 \%$ of trees near the streets have to be controlled by Visual Tree Assessment (VTA) $)^{45}+$ instrumental analysis that constituted the main operative procedure adopted in arboriculture field ${ }^{40,46}$. In a scenario where this approach is followed, $\left(\mathrm{n}^{\circ} 2\right)$ tree stability controls techniques can be differentiated according to the local TRI value. In particular, all trees with TRI greater than 1/10000 must be verified by VTA + instrumental analysis; trees with TRI under 1/10000 can be controlled by a different analysis type, the so called punctual quickly assessment (PQA), developed by Italian Group of Tree stability assessors (SICURAMENTEALBERI) ${ }^{15}$ that represent a standard for tree management in extensive contexts in Italy. PQA is a more burdensome analysis that consider only few parameter to evaluate tree stability and determining minor unitary costs respect to VTA. The comparison of two scenarios (Tab. 4) shows 69\% of economic saving adopting the proposed methodology in respect of the ordinary procedure.

Table 4 - Technological transfer scenarios. Comparison between the ordinary tree risk control methodology (1) and the proposed one (2).

\begin{tabular}{|c|c|c|c|c|}
\hline & Scenarios $\mathbf{n}^{\circ}$ & Tree Stability assessment & $\begin{array}{c}\text { Unitary Cost } \\
€ / \text { tree * }\end{array}$ & $\begin{array}{c}\% \text { of } \\
\text { Considered Trees }\end{array}$ \\
\hline \multirow{3}{*}{ 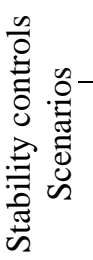 } & (1) & VTA + instrumental analysis & 14 & 100 \\
\hline & & VTA + instrumental analysis & 14 & 57 \\
\hline & & PQA & 4 & 43 \\
\hline
\end{tabular}

Future develops will expect to test the methodology proposed in urban forestry context using traffic fluxes available for Piemonte Region to better calibrate TE. A comparison between SI and ground-based tree stability index is necessary to calibrate the remotely sensed methodology on ground true and refining the method increasing model accuracies.

\section{REFERENCES}

1. S. Roy, J. Byrne, and C. Pickering, "A systematic quantitative review of urban tree benefits, costs, and assessment methods across cities in different climatic zones," Urban Forestry \& Urban Greening 11(4), 351-363 (2012) [doi:10.1016/j.ufug.2012.06.006].

2. M. G. Stewart, D. O'Callaghan, and M. Hartley, "Review of QTRA and risk-based cost-benefit assessment of tree management," Arboriculture \& Urban Forestry 39(4), 165-172 (2013).

3. J. Barrell, "Balancing tree benefits against tree security: The duty holder's dilemma," Arboricultural Journal 34(1), 29-44 (2012) [doi:10.1080/03071375.2012.691674].

4. J. Pokorny et al., "Urban tree risk management: a community guide to program design and implementation," USDA Forest Service Northeastern Area State and Private Forestry 1992 Folwell Ave. St. Paul, MN 55108 (2003).

5. R. R. HSE, "Protecting People," HSE’s decisionmaking process. Crown, London (2001). 
6. National Tree Safety Group, Great Britain, and Forestry Commission, Common sense risk management of trees: guidance on trees and public safety in the UK for owners, managers and advisers., Forestry Commission, Edinburgh (2011).

7. T. W. Schmidlin, "Human fatalities from wind-related tree failures in the United States, 1995-2007," Natural Hazards 50(1), 13-25 (2009).

8. V. H. Dale et al., "Climate change and forest disturbances: climate change can affect forests by altering the frequency, intensity, duration, and timing of fire, drought, introduced species, insect and pathogen outbreaks, hurricanes, windstorms, ice storms, or landslides," BioScience 51(9), 723-734 (2001).

9. S. E. Gill et al., "Adapting Cities for Climate Change: The Role of the Green Infrastructure," Built Environment 33(1), 115-133 (2007) [doi:10.2148/benv.33.1.115].

10. O. Holdenrieder et al., "Tree diseases and landscape processes: the challenge of landscape pathology," Trends in Ecology \& Evolution 19(8), 446-452 (2004).

11. D. J. Ball, "WHY RISK ASSESSMENT NEEDS AN UNDERPINNING PHILOSOPHY," Arboricultural Journal 30(2), 113-119 (2007) [doi:10.1080/03071375.2007.9747485].

12. A. K. Koeser et al., "Municipal tree risk assessment in the United States: Findings from a comprehensive survey of urban forest management," Arboricultural Journal 38(4), 218-229 (2016) [doi:10.1080/03071375.2016.1221178].

13. A. L. Shigo, Modern arboriculture, Shigo and Trees, Associates (1994).

14. M. A. Gomarasca, Basics of geomatics, Springer Science \& Business Media (2009).

15. AAVV, "PROCEDURE PER LA GESTIONE DEL RISCHIO DA CADUTA ALBERI NELLE AREE VERDI ESTENSIVE," GRUPPO DI LAVORO "SICURAMENTEALBERI" (2011).

16. E. T. Smiley, N. Matheny, and S. Lilly, BMP best management practices: tree risk assessment., International Society of Arboriculture (2017).

17. M. Ellison, "MOVING THE FOCUS FROM TREE DEFECTS TO RATIONAL RISK MANAGEMENT-A PARADIGM SHIFT FOR TREE MANAGERS," Arboricultural Journal 30(2), 137-142 (2007) [doi:10.1080/03071375.2007.9747488].

18. M. J. Ellison, "Quantified tree risk assessment used in the management of amenity trees," Journal of Arboriculture 31(2), 57-654 (2005).

19. G. Sinn and L. Wessolly, "A contribution to the proper assessment of the strength and stability of trees," Arboricultural Journal 13(1), 45-65 (1989).

20. L. Wessolly and M. Erb, Handbuch der Baumstatik+ Baumkontrolle, Patzer (1998).

21. J. Lisein et al., "A Photogrammetric Workflow for the Creation of a Forest Canopy Height Model from Small Unmanned Aerial System Imagery,” Forests 4(4), 922-944 (2013) [doi:10.3390/f4040922].

22. B. St-Onge, F.-A. Audet, and J. Bégin, "Characterizing the Height Structure and Composition of a Boreal Forest Using an Individual Tree Crown Approach Applied to Photogrammetric Point Clouds," Forests 6(12), 3899-3922 (2015) [doi:10.3390/f6113899].

23. A. Zambarda, M. Černỳ, and P. Vopěnka, "Field-map-the new technology designed by IFER for the collection and processing of forest inventory data.," Sherwood-Foreste ed Alberi Oggi(167), 33-38 (2010).

24. M. Isenburg, "LAStools-efficient tools for LiDAR processing," Available at: http: http://www. cs. unc. edu/ isenburg/lastools/[Accessed October 9, 2012] (2012).

25. D. C. Bragg, "Accurately Measuring the Height of (Real) Forest Trees," Journal of Forestry 112(1), 51-54 (2014) [doi:10.5849/jof.13-065].

26. D. R. Larsen, D. W. Hann, and S. C. Stearns-Smith, "Accuracy and precision of the tangent method of measuring tree height," Western Journal of Applied Forestry 2(1), 26-28 (1987).

27. E. Abramo, A. Barilotti, and F. Sepic, "Dalla dendrometria diametrica alla dendrometria ipsometrica: stima del volume degli alberi da rilievi laser-scanning," Forest@-Journal of Silviculture and Forest Ecology 4(4), 373 (2007).

28. K. J. Niklas, "The mechanical role of bark," American Journal of Botany 86(4), 465-469 (1999).

29. A. van Laar and A. Akça, Forest mensuration, 2. ed., completely rev. and supplemented, Springer, Dordrecht (2007).

30. V. Lobis et al., "Valutazione della stabilità degli alberi: il SIA (Statistics Integrated Assessment) ed il metodo SIM (Statistics Integrated Method)," Sherwood(78), 41-46 (2002).

31. S. Testa et al., "MODIS-derived EVI, NDVI and WDRVI time series to estimate phenological metrics in French deciduous forests," International journal of applied earth observation and geoinformation 64, 132-144 (2018).

32. B. A. Bradley et al., "A curve fitting procedure to derive inter-annual phenologies from time series of noisy satellite NDVI data," Remote Sensing of Environment 106(2), 137-145 (2007). 
33. N. Pettorelli et al., "Using the satellite-derived NDVI to assess ecological responses to environmental change," Trends in ecology \& evolution 20(9), 503-510 (2005).

34. R. E. Burgan and R. A. Hartford, "Monitoring vegetation greenness with satellite data," Gen. Tech. Rep. INT-GTR297. Ogden, UT: US Department of Agriculture, Forest Service, Intermountain Research Station. 13 p. 297 (1993).

35. B.-C. Gao, "NDWI-A normalized difference water index for remote sensing of vegetation liquid water from space," Remote sensing of environment 58(3), 257-266 (1996).

36. J. P. Ormsby, B. J. Choudhury, and M. Owe, "Vegetation spatial variability and its effect on vegetation indices," International Journal of Remote Sensing 8(9), 1301-1306 (1987).

37. X. Zhang et al., "Monitoring vegetation phenology using MODIS," Remote sensing of environment 84(3), 471-475 (2003).

38. N. Anselmi and G. Govi, Patologia del legno, Edagricole (1996).

39. J. Oliva et al., "Concepts of epidemiology of forest diseases.," in Infectious forest diseases, P. Gonthier and G. Nicolotti, Eds., pp. 1-28, CABI, Wallingford (2013) [doi:10.1079/9781780640402.0001].

40. F. W. M. R. Schwarze, J. Engels, and C. Mattheck, Fungal Strategies of Wood Decay in Trees, Springer Science \& Business Media (2013).

41. R. A. Zabel and J. J. Morrell, Wood Microbiology: Decay and Its Prevention, Academic Press (2012).

42. N. P. Matheny and J. R. Clark, "A photographic guide to the evaluation of hazard trees in urban areas," International Soc. Arboriculture: Savoy, Illinois. 2nd edn. 85pp 634 (1994).

43. D. R. Helliwell, "Acceptable levels of risk associated with trees," Arboricultural Journal 14(2), 159-162 (1990).

44. C. J. Willmott and K. Matsuura, "Advantages of the mean absolute error (MAE) over the root mean square error (RMSE) in assessing average model performance," Climate research 30(1), 79-82 (2005).

45. C. Mattheck and H. Breloer, The body language of trees: a handbook for failure analysis., HMSO Publications Centre (1994).

46. K. Bethge, C. Mattheck, and E. Hunger, "Equipment for detection and evaluation of incipient decay in trees," Arboricultural Journal 20(1), 13-37 (1996).

47. Regione Piemonte, "Prezziario Opere Pubbliche regione piemonte 2018” (2018). 